\title{
ÓRGANOS DE CONTROL
}

os órganos encargados de hacer el seguimiento, vigilancia y control de la eficiencia y efectividad del SARLAFT son la revisoría fiscal y la auditoría interna o el ente asignado para hacer esta función.

\subsection{Revisoría fiscal}

Adicional a las demás funciones que esta área tiene asignadas, en materia de SARLAFT debe hacer trimestralmente una auditoría a los resultados de medición y control del área de cumplimiento, para con ello evidenciar las fortalezas y debilidades, y sugerir las oportunidades de mejora a que haya lugar.

De los hallazgos que en materia de SARLAFT evidencien falencias, deberá emitir informe inmediato al oficial de cumplimento y asesorarlo en la estructuración de un plan de mejoras.

De todo lo anterior, la revisoría fiscal deberá dejar como constancia un informe que ha de ser remitida a la junta directiva.

\subsection{Auditoría interna o quien ejecute funciones similares o haga sus veces}

En materia de SARLAFT, la auditoría interna debe hacer una valoración anual de todas y cada una de las etapas que conformar este sistema, con la finalidad de identificar debilidades y sus posibles oportunidades de mejora. De los hallazgos se debe remitir un informe al oficial de cumplimento, indicando los controles sugeridos a implementar.

Una de las actividades propias de la auditoría es la de analizar la viabilidad de las medidas de exoneración y parametrización de las metodologías, modelos e indicadores cualitativos y/o cuantitativos de valor técnico. 


\title{
CONCLUSIONES
}

\begin{abstract}
\rceil
eniendo en cuenta que, si bien el SARLAFT es una buena herramienta contra la materialización de delitos subyacentes al lavado de activos y la financiación del terrorismo, esta no evita en un 100\% la utilización de las empresas para la ejecución de dichos actos criminales. Por esto deben aunarse de forma permanente todos los esfuerzos necesarios para fortalecer el sector económico nacional y mitigar los riesgos inherentes a cada tipo de actividad de capital. Por lo tanto, es menester que las empresas, dentro de sus áreas de cumplimiento:
\end{abstract}

$\times$ Cuenten con equipos de abogados expertos en delitos empresariales que les permitan una efectiva y eficiente identificación de operaciones inusuales y sospechosas.

× Se mantengan en constante actualización en materia de políticas nacionales e internacionales que sobre la materia se expidan para la identificación de las nuevas tipologías de señales de alerta.

× Implementen tecnología para la segmentación de las operaciones de los clientes, dependiendo de las características de las actividades económicas y productos que consuman.

Precisamente, en cuanto a las herramientas tecnológicas con las que debe contar un oficial de cumplimiento, para el buen ejercicio de sus actividades, han salido al mercado nuevos productos en materia de inteligencia artificial que ofrecen programas diseñados para no ser intervenidos por las partes o terceros, lo que facilita la mitigación de actos de mala fe y riesgos de pérdida en materia de negocios.

Estos programas están en la capacidad de revisar y redactar contratos mercantiles, en grandes cantidades y en tiempos nunca alcanzados por seres humanos, con un mínimo margen de error, hacen negociación con activos digitales (criptomoneda, títulos valores virtuales, pagos nacionales 
e internacionales, entre otros), protegen los datos de los clientes, proyectan posibles riesgos de incumplimiento contractual, violaciones a normas nacionales e internacionales, verifican nombres e identificaciones de clientes en centrales de riesgo e incluso pueden programarse para segmentar las operaciones de estos, lo que facilita la identificación de operaciones inusuales y la definición de nuevas tipologías de señales de alerta.

La implementación de estas tecnologías hace más eficiente y efectiva la actividad propia de las áreas de cumplimiento en cuanto a su labor operativa, por lo que pueden dedicarse a la elaboración de nuevas estrategias de mitigación de riesgos, interpretación de operaciones inusuales y profundización de la gestión de conocimiento del cliente.

Según el informe Basel AML Index 2017, referenciado por la revista portafolio en el mes de agosto del mismo año, la implementación de este tipo de tecnologías en Colombia le permitió posicionarse muy bien en la calsificación de los países con menor riesgo de lavado de activos en Latinoamérica, tanto así que se encuentra en la posición 125 de 146, con una calificación de 4,5 sobre 10 (menor cifra indica menor riesgo), esto ha convertido a la nación en un atractivo para la inversión extranjera, lo que correlativa e irónicamente la hace llamativa para las bandas dedicadas a los delitos económicos, por lo que este proceso debe ser permanente y dialéctico. 